\title{
Visuospatial working memory in Parkinson's disease
}

\author{
VERONICA A BRADLEY, JOHN L WELCH, DAVID J DICK \\ From the Regional Neurological Centre, General Hospital, Newcastle upon Tyne
}

SUMMARY Visuospatial impairment is frequently reported in Parkinson's disease but the psychological mechanisms which subserve the impaired abilities and the way in which breakdown of the mechanisms leads to performance deficits have not been precisely delineated. This paper reports experimental investigations designed to test the hypothesis that the locus of the impairment is the visuospatial subsystem of working memory. Subjects were a group of sixteen patients with Parkinson's disease of mild to moderate severity and a matched control group. They performed complex visuospatial and verbal memory tasks. The Parkinsonian group were significantly slower than the control group when performing the visuospatial task. They were not significantly slower and made no more errors than the control group on the verbal task. The findings are compatible with the hypothesis that the visuospatial subsystem of working memory is impaired in Parkinson's disease. It is demonstrated that the impairment is not the result of a reduction in the capacity of this subsystem but is due to difficulty in utilising information stored in the subsystem to perform complex visuospatial tasks.

In spite of different estimates of the prevalence of intellectual impairment in Parkinson's disease (PD) and varying accounts of the precise nature of such impairment there are themes which recur constantly in the ever increasing literature relating to the issue of intellectual impairment in PD. In particular the presence of specific cognitive impairment, distinct from the global impairment mimicking an Alzheimer type dementia which is sometimes associated with PD in its later stages, has received much consideration. Boller ${ }^{1}$ reviews a number of papers which report a specific deficit in PD patients when compared with normal controls. These papers find an impairment "mainly in tasks that require what can generally be called visuospatial functions". Boller emphasises that this is a "specific, well-delineated deficit" rather than a "true dementia". Mayeux ${ }^{2}$ notes "the high frequency of perceptual motor or visuospatial impairment reported in association with PD" and concludes that these reports suggest that many individuals with PD develop a disturbance in visuospatial discrimination and that the presence of unique deficits does not

Correspondence to: $\operatorname{Dr} \mathrm{V}$ A Bradley, Department of Clinical Psychology, Regional Neurological Centre, Newcastle General Hospital, Newcastle upon Tyne NE4 6BE, United Kingdom.

Received 14 October 1988 and in revised form 3 March and 5 June 1989.

Accepted 17 July 1989 warrant a diagnosis of dementia. Similar conclusiong are reached by other major reviewers. ${ }^{34}$

However, findings which provide evidence specific visuospatial impairment are by no mean universal. Table 1 lists major studies which have addressed this issue. It can be seen that a considerablo range of clinical tests and experimental tasks have been used and in many cases no precise definition of the term "visuospatial abilities" is provided. Under these circumstances the ambiguity of the findings is perhaps unsurprising.

It is clear that further investigations relating to the presence of a visuospatial deficit in PD would be facilitated by a theoretically-motivated description of the deficit. The majority of investigations of cognitive deficits in PD have used clinical tests and even where experimental tasks have been designed for this purpose no detailed psychological model of visuospatial function has been proposed to provide a framework for the investigation. Boller's group ${ }^{8}$ go some way towards defining the hypothesised impairment of visuospatial function in PD. The impairment encompasses "difficulty in appreciating the relative position of stimulus - objects in space, difficulty in integrating those objects into a coherent spatial 옥 framework and difficulty in performing mental opera- $D$ tions involving spatial concepts". However, the psy- 을. chological mechanisms implicated in the abilities listed $N$ and the way in which breakdown of the mechanisms 
Table 1 Studies investigating specific visuospatial impairment in PD

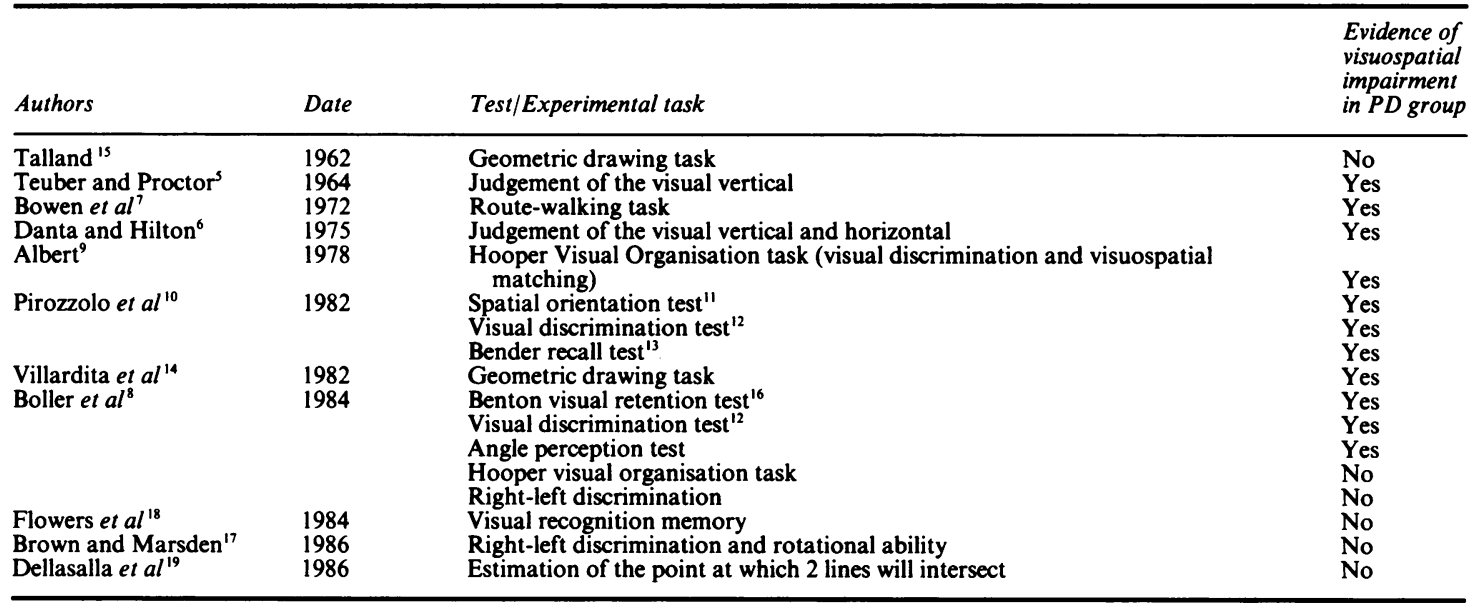

could lead to performance deficits are issues which are not addressed. The literature on visual perception and visual memory in normal subjects is a source of numerous hypotheses and models many of which have proved to be applicable in neuropyschological research (for example, into impaired object constancy) $;{ }^{21}$ however, the majority of models tend to focus on one particular aspect of visual perception (for example, pattern recognition; ${ }^{22}$ visual shape recognition ${ }^{23}$ ). They are thus not of great value in the investigation of a disorder such as PD in which a range of visuospatial deficits have been observed.

The model which is felt to be most appropriate to the current investigation is the model of working memory developed by Baddeley and his coworkers. ${ }^{24-26}$ Baddeley proposes that working memory consists of a number of inter-related systems, the three principal components being the Central Executive System (CES), the Articulatory Loop System (ALS) and the Visuospatial Sketchpad (VSSP). The CES controls and coordinates the other subsystems and is assumed to function like a "limited-capacity attentional system". ${ }^{27}$ The ALS is concerned with storage of auditory speech input or subvocal speech and has been investigated extensively. ${ }^{28}$ The VSSP is concerned with maintaining and manipulating visuospatial material. There is some evidence that the system is primarily spatial rather than visual in nature $^{25}$ although some doubt is cast upon this conclusion by the finding that when two tasks must be performed concurrently any unattended visual material interfered with performance on a primary visuospatial task. ${ }^{31}$ It has also been demonstrated that spatial imagery mnemonics rely on the VSSP. ${ }^{25}$ Baddeley ${ }^{26}{ }^{27}$ suggests that the VSSP comprises a store linked with a rehearsal process.
It is hypothesised that the locus of impairment in PD is the visuospatial subsystem of working memory. This hypothesis is compatible with certain reports of negative findings when experimental tasks do not have a memory component for example ${ }^{1719}$ although elaboration of the hypothesis would be required to account for positive findings on such tasks. Additionally the type of demands made on visuospatial working memory by different tasks may account for other negative findings since, if visuospatial working memory is not a unitary system as Baddeley suggests, different components of the system may be differentially impaired. The following investigation utilises tasks which depend upon visuospatial working memory to test the hypothesis.

\section{Experiment 1: visual and auditory span}

Baddeley ${ }^{26}{ }^{27}$ argues that there may be an analogy between the VSSP and the fiLS and that both systems may comprise an essentially passive perceptual input store and a rehearsal mechanism. In investigating the ALS Morris ${ }^{30}$ found that, although verbal memory span was reduced in AD patients, the ALS appeared to be unimpaired. He concluded that his results suggest that the impairment in short-term memory must result from dysfunction within the memory system outside the ALS. An alternative possibility, with which Morris' findings seem to be compatible, is that the passive store is limited in its capacity although the articulatory rehearsal mechanism is intact. In view of the possible dissociation between storage capacity and rehearsal/processing mechanisms the first step in the investigation was to obtain a measure of memory span before utilising tasks which required storage in memory over a period of time and complex processing (active scanning of the contents of working memory is required in the other experimental tasks). Subjects A group of subjects with PD were selected from a cohort investigated at Newcastle General Hospital who had 
agreed to participate in a series of experimental studies. All subjects had been diagnosed as being in the mild-to-moderate stages of the disease. Patients showing evidence of significant decline in cognitive function or evidence of more than very mild depression were excluded. The criteria for exclusion on the basis of depressed affective state was a score greater than 13 on the Hamilton Rating Scale for Depression which was administered following an initial diagnosis by a psychiatrist. As regards decline in cognitive function the criteria for exclusion were a 37-point Mental Test Score of less than 30 (max score 37) and/or a WAIS Full Scale IQ score or an IQ equivalent score on Raven's Progressive Matrices which was more than 15 points below the full-scale premorbid IQ predicted by the National Adult Reading Test (NART). All subjects were receiving dopaminergic medication and many were also receiving anticholinergic treatment. Patients were rated for severity of Parkinsonian symptoms at the time of the experimental investigation. The Webster Rating Scale ${ }^{32}$ was used and all patients had symptoms of mild-to-moderate severity. The experimental group consisted of 16 subjects, age range 55-77 years (mean age, 66). The group contained 12 males and four females. Profiles of the 16 experimental subjects are provided in Table 2. A control group of 16 subjects matched with the PD group on the basis of age, sex, range of occupation and years of education was formed.

Materials and Procedure Verbal memory span was assessed by means of the Digits Forward Subtest of the Wechsler Memory Scale. ${ }^{33}$ Visual memory span was assessed by means of a computerised task (Blox) developed by Lindsay Wilson at the University of Stirling. Stimuli in this task are patterns composed of boxes which may be either filled or unfilled. Filling the box produces a solidly illuminated rectangle. The first pattern presented consists simply of two boxes, one below the other, with one box filled. Pattern complexity is increased in steps of two boxes at a time, half the boxes being illuminated at random at each level of complexity. The boxes fill simultaneously; sequential information is excluded in this version of the task. The boxes are arranged irregularly on the screen, the second and third pair of boxes appearing beside the first pair but not strictly aligned with them and subsequent pairs appearing lower on the screen. The arrangement of boxes varies slightly at each presentation. $\bar{Z}$ The stimulus pattern is presented for $100 \mathrm{msec}$ and the filled $\Phi$ boxes are then cleared. The subject must then touch the boxes which were filled (unfilled boxes fill when touched). The boxes may be touched in any order. There is no delay between presentation and response. Feedback is given after the $O$ response to a complete pattern has been made (the computer

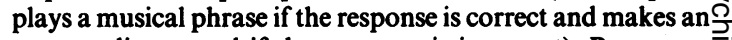
unrewarding sound if the response is incorrect). Responses, are recorded by means of a touch sensitive screen. In this case a Microvitec Touchtec 501 screen was used and the programme was run on a BBC-B computer. (It was necessary to obtain additional memory capacity before the programmewould run on a BBC-B and this capacity was obtained by the $\frac{-}{\sigma}$ addition of a Raven ROM board). Three trials are adminis- $\overline{\bar{c}}$. tered at each level and the subject proceeds to the next level if $\vec{\Phi}$ he has responded correctly in at least one trial at theo preceding level. Failure on all three trials at any level terminates the programme. Span is taken to be the number of $\overrightarrow{ }$ filled boxes at the highest level of complexity at which the? subject produces a correct response.

The literature on the assessment of visual span describes $\vec{\omega}$ the use of a number of different tasks each of which elicits a different mean span in a normal group. ${ }^{34} 35$ The Blox task was selected because it yields scores in the same range as auditory span tasks implying a similar level of difficulty although there? is no evidence that task requirements are identical.

Results and analysis of results The mean auditory and visugl $-\overrightarrow{ }$ span scores for the PD and control groups are shown in TablN 3. A two-way repeated measure analysis of variance vâns $\infty$ performed on the span scores with modality (two levels auditory/visual) as the within-subject factor and group as between-subject factor. There was no significant interactionn $Z$ between group and modality $(F(1,28)<1, p>0.05)$ and po significant effect of group $(\mathrm{F}(1,28)=1.99, \mathrm{p}>0.05) \underset{\mathrm{\Phi}}{\mathrm{r}}$ modality $(F(1,28)<1, p>0.05)$.

Discussion Results of the span tasks indicate that ang impairment in visuospatial functioning in Parkinsonian $\overrightarrow{0}$ patients cannot be explicable in terms of reduced visualo memory span. The span scores of the PD group were not significantly lower than the span scores of the control group.

Table 2 Profiles of the Parkinson's disease subjects

\begin{tabular}{|c|c|c|c|c|c|c|c|}
\hline Subject & Age & Sex & Handedness & $\begin{array}{l}\text { Years of } \\
\text { education }\end{array}$ & Best occupation & $\begin{array}{l}\text { Date of } \\
\text { onset of } P D\end{array}$ & $\begin{array}{l}\overrightarrow{\bar{D}} \\
\stackrel{ }{3} \\
\overline{2}\end{array}$ \\
\hline $\begin{array}{r}1 \\
2 \\
3 \\
4 \\
5 \\
6 \\
7 \\
8 \\
9 \\
10 \\
11 \\
12 \\
13 \\
14 \\
15 \\
16\end{array}$ & $\begin{array}{l}73 \\
69 \\
77 \\
65 \\
60 \\
59 \\
64 \\
55 \\
66 \\
68 \\
70 \\
62 \\
61 \\
72 \\
67 \\
66\end{array}$ & $\begin{array}{l}\mathbf{F} \\
\mathbf{M} \\
\mathbf{F} \\
\mathbf{M} \\
\mathbf{M} \\
\mathbf{F} \\
\mathbf{M} \\
\mathbf{M} \\
\mathbf{M} \\
\mathbf{M} \\
\mathbf{M} \\
\mathbf{M} \\
\mathbf{M} \\
\mathbf{F} \\
\mathbf{M} \\
\mathbf{M}\end{array}$ & $\begin{array}{l}\mathbf{R} \\
\mathbf{R} \\
\mathbf{R} \\
\mathbf{R} / \mathbf{L} \\
\mathbf{R} \\
\mathbf{R} \\
\mathbf{R} \\
\mathbf{R} \\
\mathbf{R} \\
\mathbf{R} \\
\mathbf{R} \\
\mathbf{R} \\
\mathbf{R} \\
\mathbf{L} \\
\mathbf{R} \\
\mathbf{R}\end{array}$ & $\begin{array}{r}9 \\
9 \\
9 \\
9 \\
11 \\
9 \\
9 \\
9 \\
9 \\
9 \\
11 \\
9 \\
9 \\
11 \\
9 \\
9\end{array}$ & $\begin{array}{l}\text { Housewife } \\
\text { Foreman gardener (LA) } \\
\text { School meals service } \\
\text { Plumber's mate } \\
\text { School teacher (Maths) } \\
\text { Barmaid } \\
\text { Bus driver } \\
\text { Fireman } \\
\text { Farmer } \\
\text { Cartographer } \\
\text { Civil Service (clerical officer) } \\
\text { Production worker (Glass factory) } \\
\text { Builder's labourer } \\
\text { Shop assistant (Baker's) } \\
\text { Grinder } \\
\text { Manager (shop filling station) }\end{array}$ & $\begin{array}{l}1978 \\
1972 \\
1981 \\
1976 \\
1970 \\
1977 \\
1966 \\
1984 \\
1975 \\
1980 \\
1984 \\
1981 \\
1984 \\
1978 \\
1966 \\
1979\end{array}$ & 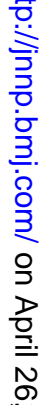 \\
\hline & & & & & & & 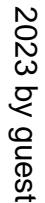 \\
\hline
\end{tabular}


Table 3 Mean Auditory and Visual Span Scores

\begin{tabular}{lllll}
\hline & \multicolumn{1}{c}{ PD Group } & \multicolumn{2}{c}{ Controls } \\
\hline Auditory Span & 6.5 & $(1.2)$ & 6.8 & $(1.3)$ \\
Visual Span & 6.5 & $(1.2)$ & $7 \cdot 1$ & $(1 \cdot 1)$ \\
\hline
\end{tabular}

SD in parentheses.

\section{Experiment 2: "complex" visuospatial processing}

The majority of tasks in which PD patients have been shown to be impaired involve delayed recall and/or manipulation of the material stored in working memory. The tasks developed for use in the present study require decision-making on the basis of material stored in working memory. One task is primarily visuospatial; the other is a verbal analogue of this task. It is hypothesised that the PD group will perform less well on the former than on the latter task.

Subjects The PD and control groups described in the previous experiment performed the tasks.

Materials and procedure Tasks are computerised, being presented on a Commodore 64 microcomputer. The primary visuospatial task requires memorisation of a simple route or "road" which joins two coloured squares or "houses" which appear on the monitor. The subject must then decide whether turns in the road are right or left turns. The sequence of events is as follows:-1) Two filled squares are shown on the monitor. One is coloured red, the other blue, and their position is constant. The squares or "houses" are joined by a solid line or "road" which has two right-angled turns in it. The six possible designs which comprise two turns are presented in random order although the presentation of identical designs consecutively is avoided. Roads with up to four turns were originally included in the test but after the initial trials roads with more than two turns were not included since these items proved very difficult even for cognitively unimpaired individuals. The road is displayed on the monitor for 10 seconds. 2) The screen is then cleared and the subject is asked to reproduce the road by drawing it on a piece of paper on which the houses are already marked to ensure that it has been memorised. If the subject is unable to draw the road it can be recalled for a further ten seconds and the subject attempts the drawing again. The subject does not proceed further with the task until the road has been accurately memorised. 3) The subject must now imagine the road and is told "Red" or "Blue" by the experimenter (E). This tells him from which point he is to start when proceeding along the road in imagination. Withholding information about the starting point helps to ensure that responses are not encoded verbally by $S$ during initial presentation. 4) The subject responds "Yes" or "No" according to whether or not each turn in the road is a right turn ("Yes" for right turns, "No" for left). The "Yes/No" response was chosen in preference to a "Right/Left" response to dissuade subjects from verbally encoding the turns in the road on initial presentation. Responses are made by pressure on one of two metal pads, one placed so that it can be easily pressed by the right hand, the other by the left (the pad on the right was always labelled "yes" and the pad on the left "no" in order to avoid incompatibility effects which might occur if subjects were required to respond with the right hand to indicate a turn to the left). The pads were constructed by technicians at the Regional Neurological Centre, specifically for use with PD patients with tremor and including an anti-bounce device. The use of this response device minimises the motor component in the task.

Additionally, since the hands are positioned with fingers above the pads throughout the test, subjects are not tempted to stop fixating the screen to look at the pads when making responses. A tone, occurring seven seconds after the design has been memorised (E presses a key to proceed after $\mathbf{S}$ has drawn the design correctly), indicates that the computer is starting to record reaction time and signals to $\mathrm{E}$ to give the "Red/Blue" instruction. This task requires the ability to make right/left discriminations. There is no reason to suppose that PD patients are impaired in this ability. For example, Boller et al $^{8}$ found no significant difference between the scores of a PD group and a normal control group in a test of this ability (the Puppet Test, modified from Ratcliffe ${ }^{40}$ ).

The primary verbal memory task involves memorising a short phrase and then making decisions about initial letters

\begin{tabular}{|c|c|c|c|c|c|}
\hline Medication & Webster Score & $\begin{array}{l}\text { Hamilton } \\
\text { Depression } \\
\text { Rating }\end{array}$ & $\begin{array}{l}\text { Mental } \\
\text { Test Score }\end{array}$ & $N A R T$ & $\begin{array}{l}\text { Raven's Progressive } \\
\text { Matrices or WAIS }\end{array}$ \\
\hline $\begin{array}{l}\text { Madopar } \\
\text { Madopar, Artane } \\
\text { Sinemet, Pro-Banthine } \\
\text { Madopar } \\
\text { Madopar } \\
\text { Sinemet } \\
\text { Madopar } \\
\text { Orphenadrine, Parlodel } \\
\text { Madopar, Disipal, Symetrel } \\
\text { Sinemet, Tremonil } \\
\text { Levodopa, Madopar, Eldepryl, Tremonil } \\
\text { Sinemet } \\
\text { Madopar, Artane } \\
\text { Madopar } \\
\text { Sinemet } \\
\text { Sinemet, Tremonil }\end{array}$ & $\begin{array}{r}10 \\
11 \\
12 \\
10 \\
15 \\
16 \\
14 \\
12 \\
13 \\
8 \\
8 \\
16 \\
6 \\
9 \\
9\end{array}$ & $\begin{array}{r}11 \\
6 \\
12 \\
12 \\
3 \\
3 \\
4 \\
4 \\
4 \\
4 \\
5 \\
8 \\
6 \\
4 \\
3 \\
3\end{array}$ & $\begin{array}{l}37 \\
36 \\
37 \\
35 \cdot 5 \\
37 \\
35 \\
37 \\
35 \\
36 \\
37 \\
37 \\
35 \\
34 \\
36 \\
37 \\
37\end{array}$ & $\begin{array}{r}114 \\
112 \\
106 \\
87 \\
121 \\
92 \\
113 \\
106 \\
106 \\
117 \\
121 \\
102 \\
87 \\
116 \\
107 \\
112\end{array}$ & $\begin{array}{r}112 \\
104 \\
92 \\
84 \\
115 \\
91 \\
115 \\
111 \\
119 \\
118 \\
119 \\
103 \\
90 \\
114 \\
119 \\
115\end{array}$ \\
\hline
\end{tabular}


of the words in the phrase. The sequence of events is as follows:-1) A three word phrase (for example "work with wood") is shown on the monitor for ten seconds. Visuallypresented verbal material is registered within the ALS providing "the subject is able to subvocalise the items as they are presented" ${ }^{39}$ All forty five phrases differ from each other and are matched for syllable length. Only words in which the initial letter is pronounced regularly were used in constructing the phrases. 2) The screen is then blank and $S$ is asked to speak the phrase aloud to ensure that it has been memorised. The phrase may be recalled for a further ten seconds if required. When it has been memorised correctly $\mathrm{S}$ may proceed to the next stage. 3) The subject must now hold the phrase in verbal memory and is told the initial letter on which to base his decisions. The subject then responds "Yes" or "No" for each word according to whether the initial letter of the word is the same as the given letter ("Yes") or not ("No"). The response device is the same as that for the visuospatial task. One more response is required for each item in the verbal task than is required in the visuospatial task. This additional response was included with the aim of ensuring that there is a comparable memory load in the two modalities since three lines (though only two angles) must be held in working memory in order to perform the visuospatial task.

Many experimental investigations of working memory (and other modular cognitive systems) utilise the dual-task paradigm. The logic of dual-task methodology is summarised by Shallice et al:" "if two tasks use separate processing structures they can, under appropriate circumstances, be performed together with relatively little interference. On the other hand, if they require access to the same structure, dualtask performance is likely to be poor".

In order to investigate the effect of additional load on the visual and verbal subsystems of working memory and to provide additional evidence relating to locus of impairment, responses to both tasks are made under one of three conditions:

1) Visual Interference. The development of visual interference tasks is an area fraught with difficulty. The major problems are discussed by Logie. ${ }^{31}$ Many of the tasks which have been utilised in this context make demands on general purpose resources rather than having entirely visual or visuospatial requirements or involve skilled performance which can vary as a result of practice or fatigue. Logie argues that if visual interference is to parallel verbal interference then there is a need for a "very simple task that would fill a visual rehearsal buffer and require little in the way of general processing capacity". The task used in the present study was developed by Logie in order to fulfil these requirements. A random matrix pattern in five colours fills the screen of the monitor. As with the interference of this type presented by Logie $^{31} \mathrm{~S}$ has been instructed to keep his eyes open and directed towards the screen while making his response but to ignore the matrix pattern as far as possible.

2) No Interference. The screen of the monitor remains blank during the time in which $S$ is looking at it while making his responses.

3) Auditory Interference. Unattended speech has been shown to have a disruptive effect on verbal rehearsal ${ }^{39}$ This type of verbal interference was selected as being most closely analogous to the visual interference used in this study. The screen of the monitor remains blank but during the time in which $\mathrm{S}$ is making his responses a tape on which a randomised series of nonsense syllables has been recorded is played. The volume at which the tape is played is judged to correspond to the volume at which conversational speech is produced. $\mathrm{S}$ has been instructed to ignore the tape as far as possible. Nonsense syllables were those used in a dual-task paradigm by Salame and Baddeley. ${ }^{39}$

In both verbal and visuospatial tasks patterns of response are balanced across the three interference conditions to eliminate effects of response bias.

Particular care was taken to ensure that the interference tasks were passive and required minimal explanation in view of a suggestion made by Bloxham $e t \mathrm{al}^{44}$ that dopamine deficiency results in increased neural "noise" in the basal ganglia and that the behavioural consequences of this may be that PD patients always perform as if they were carrying out another task at the same time as any given task. Additionally, in terms of cognitive models this suggestion implies increased load on the CES and it was felt to be important to ensure that the secondary tasks made no demands on the CES.

The verbal task was administered first and the visual task second in each case. Subjects were given a ten minute rest break between the two tasks. Preliminary explanations stressed that the tasks were designed to investigate memory in general and that the main intention was not to rate the individual's memory capacity. Instructions and practice items preceded test trials.

\section{Results}

Median reaction times (RTs) for each subject wer selected as the most appropriate measure of centra tendency for data of which the distribution is considerably skewed. ${ }^{3738}$ Group means and standar deviations (SD) for the PD and control subjects undero each interference condition based on median RTs are shown in Table 4 and mean number of errors made in each condition are shown in Table 5 .

Three-way repeated measure analyses of variance

Table 4 Mean Reaction times-Verbal and Visuospatial Task

Verbal Task

\begin{tabular}{lllllll}
\hline \multirow{5}{*}{ Group } & \multicolumn{4}{l}{ Interference Condition } & \multicolumn{2}{l}{} \\
\cline { 2 - 7 } & \multicolumn{2}{l}{ Visual } & No & & \multicolumn{2}{l}{ Auditory } \\
\hline PD & 4.49 & $(1.30)$ & 4.7 & $(1.57)$ & 4.49 & $(1.40)$ \\
Control & 3.83 & $(0.86)$ & 3.88 & $(0.94)$ & 3.80 & $(0.90)$ \\
\hline
\end{tabular}

SD in parentheses.

Visuospatial Task

\begin{tabular}{|c|c|c|c|}
\hline \multirow[b]{2}{*}{ Group } & \multicolumn{3}{|c|}{ Interference Condition } \\
\hline & Visual & No & Auditory \\
\hline $\begin{array}{l}\text { PD } \\
\text { Control }\end{array}$ & $\begin{array}{ll}6.93 & (4 \cdot 3) \\
3 \cdot 73 & (1 \cdot 11)\end{array}$ & $\begin{array}{ll}7.23 & (3.84) \\
3.9 & (0.96)\end{array}$ & $\begin{array}{ll}7.53 & (4.53) \\
3.84 & (1)\end{array}$ \\
\hline
\end{tabular}

SD in parentheses. 
Table 5 Mean errors-Verbal and Visuospatial Task Verbal Task

\begin{tabular}{|c|c|c|c|c|c|}
\hline \multirow{3}{*}{$\begin{array}{l}\text { Group } \\
\text { PD } \\
\text { Control }\end{array}$} & \multicolumn{5}{|c|}{ Interference Condition } \\
\hline & Visual & \multicolumn{2}{|l|}{ No } & \multicolumn{2}{|c|}{ Auditory } \\
\hline & $\begin{array}{ll}2.31 & (2.28) \\
1.69 & (2.63)\end{array}$ & $\begin{array}{l}2 \cdot 81 \\
2 \cdot 00\end{array}$ & $\begin{array}{l}(2 \cdot 59) \\
(2 \cdot 37)\end{array}$ & $\begin{array}{l}1.94 \\
2.25\end{array}$ & $\begin{array}{l}(1 \cdot 84) \\
(2 \cdot 77)\end{array}$ \\
\hline
\end{tabular}

SD in parentheses.

Visuospatial Task

\begin{tabular}{|c|c|c|c|c|}
\hline \multirow{3}{*}{$\begin{array}{l}\text { Group } \\
\text { PD } \\
\text { Control }\end{array}$} & \multicolumn{4}{|c|}{ Interference Condition } \\
\hline & Visual & \multicolumn{2}{|l|}{ No } & Auditory \\
\hline & $\begin{array}{ll}4.94 & (2.82) \\
3.44 & (2.60)\end{array}$ & $\begin{array}{l}4 \cdot 69 \\
3 \cdot 38\end{array}$ & $\begin{array}{l}(2 \cdot 47) \\
(2 \cdot 60)\end{array}$ & $\begin{array}{ll}4.56 & (2.68) \\
3.75 & (2.24)\end{array}$ \\
\hline
\end{tabular}

SD in parentheses.

with task (two levels-verbal/visuospatial) and interference condition (three levels-visual/verbal/no interference) as within-subject factors and group as the between-subject factor were carried out on the reaction time data and the error data.

For reaction times the three-way interaction was not significant $(F(2,60)<1, p>0.05)$. There was a significant interaction between groups and task $(F(1,30)=8.42, p<0.01)$. There was no significant interaction between group and interference condition $(F(2,60)<1, p>0.05)$. Main effects of group and task were significant (Group: $F(1,30)=9.59$, $\mathrm{p}<0.01$; Task $\mathrm{F}(1,30)=8.29, \mathrm{p}<0.01)$. Further two-way ANOVAS were carried out to determine the significant results. Looking at group $\times$ condition for each task there was, for the verbal task, no significant interaction between group and condition $(F(2,60)$ $<1, \mathrm{p}>0.05)$, no significant difference between the reaction times of the $P D$ and control groups $(F(1,30)=3 \cdot 11, p>0.05)$ and no significant effect of condition $(F(2,60)=2 \cdot 03, p>0.05)$.

For the visuospatial task there was no significant interaction between group and condition $(F(2,60)$ $<1, \mathrm{p}>0.05$ ) and no significant effect of condition $(F(2,60)=1.97, p>0.05)$. There was a significant effect of group $(F(1,30)=10.12 p<0.01)$ with the reaction times of the PD group being slower than those of the control group. Looking at task $x$ condition for each group there was no interaction between task and condition $(F(2,75)<10.05), p>0.05$ and no significant effect of condition $(F(2,75)<1, p>0.05)$ for the PD group. There was a highly significant effect of task $(F(1,75)=39.6, p<0.001)$ for the PD group, with reaction times on the visuospatial task being slower than reaction times on the verbal task. For the control group there was no interaction between task and condition $(F(2,75)<1, p>0.05)$ and no sig- nificant effect of condition $(F(2,75)<1, p>0.05)$ nor of task $(F(1,75)<1, p>0.05)$.

For errors the three-way interaction was not significant $(F(2,60),<1, p>0.05)$. There were no significant two-way interactions (Group $\times$ Task; $F$ $(1,30)=1.43, \mathrm{p}>0.05)$; Group $\times$ Condition: $F$ $(2,60)=2.22, \quad p>0.05 ;$ Task $\times$ Condition $F$ $(2,60)=1 \cdot 21, \mathrm{p}>0.05)$. There was a highly significant main effect of task $(F(1,30)=31.58$, $p<0.001)$ with more errors being made on the visuospatial than on the verbal task. There were no significant main effects of group or condition (Group: $F(1,30)=1 \cdot 15, p>0.05$; Condition $F(2,60)<1$, $\mathrm{p}>0.05)$.

The PD group responded more slowly than the control group in the visual but not the verbal task. There was no significant difference between the RTs of the control group on the verbal and on the visuospatial task but the PD group had longer reaction times on the visuospatial than on the verbal task. Both PD and control groups made more errors on the visuospatial than on the verbal task. The prediction that a secondary task in the same modality would produce a greater decrement than a secondary task in a different modality from the primary task was not supported. In fact there was no significant effect of interference in either modality in the control group or the PD group.

\section{Discussion}

Comparison of performance on the verbal and the visuospatial tasks by PD and control groups showed that the PD group had longer reaction times on the visuospatial task. While the control group's speed of response was stable across tasks the PD group's RTs were much slower on the visuospatial than they were on the verbal task. The motor component in both tasks is minimal and the PD group's speed of response on the verbal task (which was not significantly slower than that of the control group) supports the claim that slower RTs on the visuospatial task were not due to the motor component in the task.

There are two possibilities which must be excluded before this result can be interpreted as indicative of a specific visuospatial impairment in the PD group. Firstly, the tasks were always presented in the same order (the task requirements for the verbal task being slightly more easily explained than those for the visuospatial task). The possibility of fatigue effects being a significant factor in slowing the performance of the PD group is very small since subjects were rested between tasks. Secondly, although the tasks were designed to be as closely equivalent as possible, it may be that the visuospatial is in fact the more difficult task and that the PD group were more sensitive to increased level of difficulty. If the visuospatial task is 
more difficult then some decrement in performance on this task as compared with the verbal task might have been expected in the control group unless they had reached ceiling on the task. In fact RTs for the control group were no longer for the visuospatial than for the verbal task although the control group's rate of error increased on the visuospatial task so that level of difficulty cannot be totally excluded as a contributory factor. A further problem of interpretation relating to level of difficulty concerns the resources which the individual is able to allocate to a given task. Brown and Marsden ${ }^{43}$ discuss this issue in relation to Parkinson's disease and argue that two tasks which differ in difficulty may be performed equally well if the subject has sufficient resources to perform the more difficult task. It may be that the PD group did not have sufficient resources for the more difficult task while the control group had sufficient resources for either task at least in terms of speed of performance. This issue could usefully be the subject of further research. Level of difficulty could be increased in both the verbal and the visuospatial task and the rate of decline in performance with increased difficulty could be compared in a PD and a control group in order to establish whether performance on both types of task falls off more rapidly in the former group and whether, at levels of difficulty high enough to stretch the resources of the control group, there is evidence of the visuospatial task being the more difficult.

With respect to the absence of an interference effect when main and interference tasks were presented in the same modality, explanations in terms of the timing and nature of the interference tasks may account for this finding. In the context of the evidence available in the literature the absence of an interference effect in the auditory interference condition of the verbal task is more surprising than the absence of an effect of visual interference in the visuospatial task. A substantial effect of unattended speech on memory for visually presented verbal material has been demonstrated repeatedly. ${ }^{394142}$ Timing of presentation has been shown to be relevant in investigations of the ALS. ${ }^{29}$ It may be that the crucial time at which interference may occur when verbal material is presented visually is during initial presentation at which point the material is being phonologically coded into the ALS. Since the stimulus material for the primary task was itself presented visually it was not possible for visual interference to occur at the time of presentation. It was necessary for the timing of the auditory interference to be identical to that of the visual interference in order that there should be parallel task demands in the two modalities. The visual interference technique used in the verbal and visuospatial tasks is still at an early stage of development and the absence of a dual-task decrement in this modality is therefore less surprising.
Baddeley and Lieberman ${ }^{25}$ suggest that the VSSP is primarily spatial rather than visual in nature. On the basis of work which found evidence of interference using a visual rather than a visuospatial task, ${ }^{31}$ Baddeley concludes that "the difficulty previously observed in demonstrating non-spatial disruption stemmed from the particular memory tasks used". Primary tasks which "rely principally on detailed spatial representation' will be "most susceptible to spatial disruption". ${ }^{26}$ It may be that the primary visuospatial task used in this study has a larger spatial component than originally recognised since it requires movement within the memorised image rather than simple retention of the image while the interference used was clearly visual rather than visuospatial.

A final point regarding the absence of a dual-task decrement in the PD group relates to the suggestion made by Bloxham and colleagues that PD patients function against a background of "neural noise" so that they always perform a task as if they were carrying out another task simultaneously. ${ }^{44}$ In the context of this suggestion it is interesting to note that the PD group was no more susceptible than the control group to the introduction of a simple "passive" interference task.

\section{References}

1 Boller F. Mental Status of patients with Parkinson's Disease. Clin Neuropsychol 1980;2:157-72.

2 Mayeux R. Depression and dementia in Parkinson's Disease. I Marsden CD, Fahn S (eds). Movement disorders. London Butterworths, 1982.

3 Mortimer JA, Christensen KJ, Webster DD. Parkinsonian demen tia. In Vinken PJ, Bruyn GW, Klawans H, Frederiks JAM (eds). Handbook of clinical neurology vol 46. Amsterdam: Elsevier Science Publishers, 1985.

4 Passafiume D, Boller F, Keefe NC. Neuropsychological impairment in patients with Parkinson's Disease. In Grant I, Adams KM (eds). Neuropsychological assessment of neuropsychiatric disorders. New York, Oxford: Oxford University Press, 1986.

5 Teuber HL, Proctor F. Some effects of basal ganglia lesions in subhuman primates and men. Neuropsychologia 1964;2:85-93.

6 Danta G, Hilton RC. Judgment of the visual vertical and horizontal in patients with parkinsonism. Neurology 1975; 25:43-7.

7 Bowen FP, Hoehn MM, Yahr MD. Parkinsonism: alterations in spatial organisation as determined by a route walking test. Neuropsychologia 1972;10:355-61.

8 Boller F, Passafiume D, Keefe NC, Rogers K, Morrow L, Kim Y. Visuospatial impairment in Parkinson's Disease. Arch Neurol 1984;41:485-90.

9 Albert ML. Subcortical dementia. In Katzman R, Terry RD, Bick $\mathrm{KL}$ (eds). Alzheimer's disease, senile dementia and related disorders. New York: Raven Press, 1978.

10 Pirozzolo FJ, Hansch EC, Mortimer JA, Webster D, Kuskowsi MA. Dementia in Parkinson's Disease: a neuropsychological analyses. Brain and Cognition 1982;1:71-83.

11 Wepman JM, Turaids D. Spatial Orientation Memory Test, Manual of Directions. Palm Springs, Calif: Language Research Associates, 1975.

12 Wepman JM, Morency A, Seidl M. Visual Discrimination Test. 
Chicago: Language Research Associates, 1975.

13 Lezak MD. Neuropsychological Assessment. (2nd ed). New York, Oxford: Oxford University Press, 1983.

14 Villardita C, Smirni P, Le Pira F, Zappala G, Nicoletti F. Mental deterioration, visuoperceptive disabilities and constructional apraxia in Parkinson's Disease. Acta Neurol Scand 1982;66: 112-20.

15 Talland GA. Cognitive function in Parkinson's Disease. J Nerv Ment Dis 1962;135:196-205.

16 Benton AL. The Revised Visual Retention Text. New York: Psychological Corporation, 1963.

17 Brown RG, Marsden CD. Visuospatial function in Parkinson's Disease. Brain 1986;109:987-1002.

18 Flowers KA, Pearce I, Pearce JMS. Recognition memory in Parkinson's Disease. J Neurol Neurosurg Psychiatry 1984; 47:1174-81.

19 Dellasalla S, Di Lorenzo G, Giordano A, Spinnler H. Is there a specific visuospatial impairment in Parkinsonians? J Neurol Neurosurg Psychiatry 1986;49:1258-65.

20 Huber SJ, Shuttleworth EC, Paulson GW. Dementia in Parkinson's Disease. Arch Neurol 1986;43:987-90.

21 Riddoch MJ, Humphries GW. Neurological impairments of object constancy: the effects of orientation and size disparities. Cognitive Neuropsychology 1986;3:207-24.

22 Lindsay PH, Norman DA. Human Information Processing. New York, London: Academic Press, 1977.

23 Milner PM. A Model for Visual Shape Recognition. Psychol Rev 1974;81:521-35.

24 Baddeley AD. The psychology of memory. New York, London: Harper and Row, 1976.

25 Baddeley AD, Lieberman K. Spatial working memory. In: Nickerson RS, ed. Attention and Performance VIII. Hillsdale, New Jersey: Erlbaum, 1980.

26 Baddeley AD. Working memory. Oxford: Oxford University Press, 1986.

27 Baddeley AD. Working memory. Philos Trans $R$ Soc of Lond (Biol) 1983:B 302 311-24.

28 Baddeley AD. Memory in Dementia. (Personal communication).

29 Baddeley A, Lewis V, Vallar G. Exploring the articulatory loop. $Q$
J Exp Psychol 1984;36A:233-52.

30 Morris RS. Dementia and the functioning of the Articulatory Loop System. Cognitive Neuropsychology 1984;1:143-57.

31 Logie RH. Visuospatial processing in working memory. $Q J$ Exp Psychol 1986;38A:229-47.

32 Webster DD. Critical analysis of the disability of Parkinson's Disease. Modern Treatment 1968;5:257-82.

33 Wechsler DD, Stone CP. Wechsler Memory Scale. New York: The Psychological Corporation, 1945.

34 Wilson JTL, Scott JH, Power KG. Developmental differences in the span of visual memory for pattern. Br J Develop Psychol 1987;5:229-55.

35 Ichikawa S. Visual memory span by means of the recall of dot-inmatrix patterns. Behaviour Research Methods and Instrumentation 1982;14:309-13.

36 Shallice T, McLeod P, Lewis K. Isolating cognitive modules with the dual-task paradigm: are speech perception and production separate processes? Q J Exp Psychol 1985;37A:507-32.

37 Guilford JP. Fundamental statistics in psychology and education. New York, London: McGraw Hill, 1965.

38 Robson C. Experiment, design and statistics in psychology. Harmondsworth: Penguin Books, 1973.

39 Salame P, Baddeley AD. Disruption of short-term memory by unattended speech: implications for the structure of working memory. J Verbal Learning and Verbal Behaviour 1982;21: $150-64$.

40 Ratcliffe G. Spatial thought, mental rotation and the right cerebral hemisphere. Neuropsychologia 1979;17:49-54.

41 Colle HA, Welsh A. Acoustic masking in primary memory. $J$ Verbal Learning Verbal Behaviour 1976;15:17-32.

42 Colle HA. Auditory encoding in visual short-term recall: effects of noise intensity and spatial location. J Verbal Learning Verbal Behaviour 1980;19:722-35.

43 Brown RG, Marsden CD. Internal versus external cues and the control of attention in Parkinson's Disease. Brain 1987; 111:323-45.

44 Bloxham CA, Dick DJ, Moore M. Reaction times and attention in Parkinson's Disease. J Neurol Neurosurg Psychiatry 1987;50: 1178-83. 